\title{
EVALUATION OF ULTRASONIC RADIATION EFFECT ON ALBUMIN COAGULATION
}

An important task of the development of ultrasonic physiotherapeutic equipment is to ensure the rationed parameters of ultrasonic radiation and research the influence of this physical factor for processes occurring in the biological environment due to the effect of ultrasound. There are occur the following processes due the influence of ultrasound: microvibration on the cellular and subcellular levels, stimulation of microcirculation processes, increasing the cell membranes permeability. As a result, the concentration of various substances in the cell and its closest environment is changed. It leads to cell membranes structure changing and the cells itself. That is why in this article were researched and mathematical modeled the ultrasonic radiation influence on albumin coagulation in the biological environment with variable indices of the intensity and time of ultrasound in unmodulated mode and different temperatures of the contact aquatic environment.

It was used an ultrasound bath with an ultrasound intensity of up to $2.0 \mathrm{~W} / \mathrm{cm}^{2}$ to evaluate the effect of ultrasonic radiation on albumin coagulation. The biological environment (chicken egg) immersed in water was subjected to ultrasonic with five modes of power without modulation (continuous mode) of radiation. The frequency of the ultrasonic signal was $42 \mathrm{kHz}$. As a source of influence was used the ultrasonic bath with two ultrasonic transducers 60 watts powerful. The maximum power was $120 \mathrm{~W}$. There was a constant control of the water temperature during all experiments to keep a constant temperature value $\left(40-41^{\circ}\right)$ for each experiment.

As a result, was determined the parameters of ultrasonic influence when is the initial process of albumin coagulation is manifested. Was exposed the dependence of the changing of the protein cell membrane thickness from the time of the ultrasonic radiation.

Keywords: ultrasound, cell membrane thickness, albumin coagulation.

Надійшла до редакиіï 12 квітня 2018 року

Рецензовано

28 квітня 2018 року

\section{УДК 612.72.2+616.12-00.8.3 \\ СПЕКТРАЛЬНЫЙ МЕТОД АНАЛИЗА ВАРИАБЕЛЬНОСТИ СЕРДЕЧНОГО РИТМА}

\author{
Худякова Л. А., Багатенкова А. И., Кулахметов Д. Р. \\ Национальный технический университет Украинь «Киевский политехнический институт \\ имени Игоря Сикорского», Киев, Украина \\ E-mail:luda@phbme.kpi.ua,bogatonkoviv@inbox.ru,coolahmetov@gmail.com
}

\begin{abstract}
Проблема хронического стресса, когда имеется постоянное повышенное напряжение регуляторных систем, касается практически всего населения, но особенно важна для отдельных профессиональньх групп, труд которых сопряжен с воздействием комплекса стрессовых факторов. Это, в частности, операторь компьютерных систем, диспетчеры, водители, а также бизнесмены и административно-управленческий аппарат.

Анализ вариабельности сердечного ритма является адекватным методом оченки уровня стресса при их повседневной деятельности. В статье рассмотрена информационная технология в виде программного обеспечения, используя которую можно обрабатьввать результаты исследований вариабельности сердечного ритма, которые получены с помощью специализированного прибора и сохранены в виде числового массива данньх. Программное обеспечение написано при помощи Мatlab и исследует массив данных с помощью спектрального метода. Также проведен краткий анализ результатов.
\end{abstract}

Ключевые слова: вариабельность сердечного ритма, спектральный метод, RR-интервал.

\section{Введение}

Анализ вариабельности сердечного ритма (ВСР) является методом оценки состояния механизмов регуляции физиологических функций в организме человека, в частности, общей активности регуляторных механизмов, нейрогуморальной регуляции сердца, соотношения между симпатическим и парасимпатическим отделами вегетативной нервной системы.

Текущая активность симпатического и парасимпатического отделов является результатом реакции многоконтурной и многоуровневой системы регуляции кровообращения, изменяющей во времени свои параметры для достижения оптимального приспособительного ответа, который отражает адаптационную реакцию целостного организма. 
Адаптационные реакции индивидуальны и реализуются у разных лиц с различной степенью участия функциональных систем, которые обладают в свою очередь обратной связью, изменяющейся во времени и имеющей переменную функциональную организацию. Метод основан на распознавании и измерении временных интервалов между R-зубцами ЭКГ (R-R-интервалы), построении динамических рядов кардиоинтервалов и последующего анализа полученных числовых рядов различными математическими методами.

Методы анализа динамических рядов кардиоинтервалов можно разделить на визуальные и математические. Визуальный анализ кардиоинтервалограм (ритмограмм) был введен Д. Жемайтите (1965, 1972). Предложенная ею классификация ритмограмм до настоящего времени не потеряла своей актуальности (Миронова Т. В., Миронов В. А. 1999). Математические методы анализа можно разделить на три больших класса:

- исследование общей вариабельности (статистические методы или временной анализ);

- исследование периодических составляющих ВСР (частотный анализ);

- исследование внутренней организации динамического ряда кардиоинтервалов (автокорреляционный анализ, корреляционная ритмография, методы нелинейной динамики).

Полученные в результате анализа ВСР числовые значения (показатели ВСР) оцениваются по-разному различными исследователями в зависимости от используемой научно-теоретической концепции.

\section{Обоснование метода}

Несмотря на почти 40-летний срок применения различных методов анализа ВСР в самых разнообразных областях прикладной физиологии и клиничиской медицины, сфера их использования продолжает расширяться с каждым годом. Принципиально важным является то, что анализ ВСР не является узкоспециализированным методом для решения конкретных диагностических задач. Можно перечислить лишь несколько примеров, где он применяется для уточнения диагноза определенных заболеваний. В частности, это диагностика автономной невропатии при диабете. В подавляющем большинстве случаев речь идет об оценке неспецифических реакций организма при воздействии различных факторов или при определенных заболеваниях. Исходя из представленных научно-теоретических положений, можно условно выделить четыре направления применения методов анализа ВСР:

1. Оценка функционального состояния организма и его изменений на основе определения параметров вегетативного баланса и нейрогуморальной регуляции;

2. Оценка выраженности адаптационного ответа организма при воздействии различных стрессоров;
3. Оценка состояния отдельных звеньев вегетативной регуляции кровообращения;

4. Разработка прогностических заключений на основе оценки текущего функционального состояния организма, выраженности его адаптационных ответов и состояния отдельных звеньев регуляторного механизма.

Практическая реализация указанных направлений открывает безграничное поле деятельности, как для ученых, так и для практиков. Ниже предлагается ориентировочный и весьма неполный перечень областей использования методов для анализа ВСР и показаний к их применению, составленный на основе анализа современных отечественных и зарубежных публикаций.

1. Оценка вегетативной регуляции ритма сердца у практически здоровых людей (исходный уровень вегетативной регуляции, вегетативная реактивность, вегетативное обеспечение деятельности);

2. Оценка вегетативной регуляции ритма сердца у пациентов с различными заболеваниями (изменения вегетативного баланса, степень преобладания одного из отделов вегетативной нервной системы). Получение дополнительной информации для диагностики некоторых форм заболеваний, например, автономной нейропатии при диабете;

3. Оценка функционального состояния регуляторных систем организма на основе интегрального подхода к системе кровообращения как к индикатору адаптационной деятельности всего организма;

4. Выделение групп риска по развитию угрожающей жизни повышенной стабильности сердечного ритма;

5. Использование в качестве контрольного метода при проведении различных функциональных проб;

6. Оценка эффективности лечебнопрофилактических и оздоровительных мероприятий;

7. Оценка уровня стресса, степени напряжения регуляторных систем при экстремальных и субэкстремальных воздействиях на организм;

8. Оценка функционального состояния человекаоператора;

9. Использование в качестве метода оценки функциональных состояний при массовых профилактических (донозологических) обследованиях разных контингентов населения;

10. Прогнозирование функционального состояния (устойчивости организма) при профотборе и определение профпригодности.

Спектральные методы анализа ВСР получили в настоящее время очень широкое распространение. Анализ спектральной плотности мощности колебаний дает информацию о распределении мощности в зависимости от частоты колебаний. Применение спектрального анализа позволяет количественно 
оценить различные частотные составляющие колебаний ритма сердца и наглядно графически представить соотношения разных компонентов СР, отражающих активность определенных звеньев регуляторного механизма [1].

Анализ в частотной области (спектральная плотность мощности) показывает периодические колебания сигналов частоты сердечных сокращений в разрезе различных частот и амплитуд; а также предоставляет информацию касательно относительной интенсивности колебаний (называемой изменчивостью или мощностью) синусового ритма сердца.

Спектральный анализ мощности может быть проведён двумя способами:

a) непараметрическим методом, посредством быстрого преобразования Фурье, который характеризуется наличием дискретных пиков для отдельных частотных компонентов.

б) параметрическим методом, а именно оценкой авторегрессионной модели, приводящей к формированию непрерывного плавного спектра активности.

Параметрические, и в частности авторегрессионные, методы требуют соответствия анализируемого объекта определенным моделям. Общим для всех классических методов спектрального анализа является вопрос применения функции окна (Windowing). Основное назначение окна - уменьшение величины смещения в периодограммных спектральных оценках. Существуют определенные различия спектрального оценивания данных при использовании периодограммного метода с равномерным окном (при 256 значениях RR) и применении различных уровней межсегментного сдвига и различного числа отсчетов на сегмент.

В то время как быстрое преобразование Фурье является простым и быстрым методом, параметрический метод является более сложным и предполагает необходимость проверки того, подходит ли выбранная модель для анализа.

Спектральный анализ позволяет разложить ритмограмму на составляющие её волны и количественно оценить вклад каждой из них [2]. Математически метод производится преобразованием Фурье с построением спектрограммы и подсчётом площади спектра в выделенных частотных диапазонах.

В результате преобразования Фурье получается частотный спектр тех периодических колебаний, которые составляли исходную кривую. Представление его в графическом виде называется спектрограммой, где по оси абсцисс откладываются частоты, по оси ординат - их амплитуды, либо квадраты амплитуд, если исследуется спектр мощности сигнала. В этом случае значения по оси ординат имеют физический смысл спектральной плотности мощности сигнала (СПМ) и измеряются в единицах мощности на 1 герц. Наряду с оценкой величины пиков спектрограммы принято анализировать также спектральную мощность по диапазонам, она вычисляет- ся как площадь под кривой, которую образуют соответствующие волновые пики.

Таким образом, использование спектрального анализа при изучении последовательностей $\mathrm{R}-\mathrm{R}$ интервалов позволяет не только выявить периодические составляющие ВСР, но и оценить их удельный вес в спектре частот.

При спектральном анализе оцениваются следующие показатели: ТР (общая мощность спектра, TF) - отражает суммарный эффект воздействия на сердечный ритм всех уровней регуляции [2].

Высокие значения характерны для здоровых людей и отражают хорошее функциональное состояние сердечно-сосудистой системы, однако сверхвысокие значения этого показателя, например, повышение ТР более 16000 мс $^{2}$ характерны для некачественной записи или наличия эктопических ритмов.

Снижение наблюдается при понижении адаптационных возможностей сердечно-сосудистой системы, низкой стрессовой устойчивости организма. Среднее абсолютное значение у здоровых людей в покое: $3446 \pm 1018 \mathrm{Mc}^{2}$.

$$
T P=H F+L F+V L F+U L F
$$

HF (мощность волн высокой частоты в диапазоне от 0,4 до 0,15 Гц, Рдв) - отражает активность парасимпатического кардиоингибиторного центра продолговатого мозга. Повышение - в состоянии покоя, во время сна, при частой гипервентиляции. Снижение - при физической нагрузке, стрессе, различных заболеваниях. Среднее абсолютное значение у здоровых людей в покое: $975 \pm 203 \mathrm{мc}^{2}$.

$$
H F=\sum_{j=L_{H F l}}^{L_{H F r}} P,
$$

где LHFr и LHF1 - номера спектральных оценок, соответствующие границам диапазона $\Delta f_{H F}$

LF (мощность волн низкой частоты в диапазоне от 0,15 до 0,04 Гц, Рмв1) - отражает активность симпатических центров продолговатого мозга (кардиостимулирующего и вазоконстрикторного). Высокие абсолютные значения наблюдаются у здоровых людей. Снижение - при физической нагрузке, стрессе, различных заболеваниях. Среднее абсолютное значение у здоровых людей в покое: $1170 \pm 416 \mathrm{mc}^{2}$.

$$
L F=\sum_{j=L_{L F l}}^{L_{L F r}} P .
$$

VLF (мощность волн очень низкой частоты в диапазоне от 0,04 до 0,0033 Гц, Рмв2) - отражает активность центральных эрготропных и гуморальнометаболических механизмов регуляции сердечного ритма. Среднее абсолютное значение у здоровых людей: $765 \pm 410 \mathrm{Mc}^{2}$.

$$
V L F=\sum_{j=L_{V L F l}}^{L_{V I F r}} P .
$$

ULF (мощность волн ультранизкой частоты в диапазоне от 0, 0033 до 0 Гц) - отражает активность высших центров регуляции сердечного ритма. По- 
вышение: характерно для срыва вегетативной регуляции сердечного ритма

$$
U L F=\sum_{j=L_{U L F l}}^{L_{U L F r}} P .
$$

LF/HF (коэффициент вагосимпатического баланса) - отношение мощности волн низкой частоты (LF) к мощности волн высокой частоты (HF). Повышение - при активизации СНС. Снижение - при активизации ПСНС. Среднее абсолютное значение у здоровых людей: 0,7-1,5.

HF\% (относительное значение мощности волн высокой частоты, Рдв\%) - отражает активность парасимпатического кардиоингибиторного центра продолговатого мозга. Преобладание в структуре спектра наблюдается у здоровых людей и спортсменов. Среднее значение у здоровых людей: $35,79 \pm 14,74 \%$

$$
H F \%=\frac{H F}{T P} \times 100 \% .
$$

LF\% (относительное значение мощности волн низкой частоты, Рмв $1 \%)$ - отражает активность симпатических центров продолговатого мозга (кардиостимулирующего и вазоконстрикторного). Среднее значение у здоровых людей: 33,68土9,04\%

$$
L F \%=\frac{L F}{T P} \times 100 \% .
$$

VLF\% (относительное значение мощности волн очень низкой частоты, Рмв2\%) - отражает активность центральных эрготропных и гуморально- метаболических механизмов регуляции сердечного ритма. Среднее значение у здоровых людей: $28,65 \pm 11,24 \%$

$$
V L F \%=\frac{V L F}{T P} \times 100 \% .
$$

HF в н. е. (относительное значение мощности волн высокой частоты, выраженное в нормализованных единицах) - отражает активность парасимпатического кардиоингибиторного центра продолговатого мозга. Преобладание HF в н. е. наблюдается у здоровых людей и спортсменов. Повышение - в состоянии покоя, во время сна, при частой гипервентиляции. Снижение - при физической нагрузке, стрессе, различных заболеваниях. Среднее значение

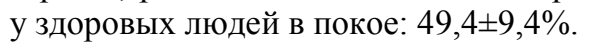

$$
\text { HFвн.е }=\frac{H F}{(T P-V L F)} \times 100 \% .
$$

LF в н. е. (относительное значение мощности волн низкой частоты, выраженное в нормализованных единицах) - отражает активность симпатических центров продолговатого мозга (кардиостимулирующего и вазоконстрикторного). Повышение при физических нагрузках, стрессе, различных функциональных или органических изменениях сердечно-сосудистой системы. Снижение - в покое, во время сна, при частой гипервентиляции. Среднее абсолютное значение у здоровых людей в покое: $50,6 \pm 9,4 \%$

$$
\text { LFвн.e }=\frac{L F}{(T P-V L F)} \times 100 \% .
$$

ИЦ (индекс централизации) - показывает отношение активности центрального контура регуляции к автономному. Вычисляется делением суммы мощностей низкочастотных волн (LF и VLF) к мощности волн высокой частоты (HF). Максимальное значение у здоровых людей в покое: 3

$$
\text { ИЦ }=\frac{L F+V L F}{H F} .
$$

Показатели ТP и LF/HF используются для оценки адаптационных возможностей регуляторных систем организма. При этом анализируется распределение объектов выделенных групп на фазовой плоскости, где по оси абсцисс откладываются значения ТР, а по оси ординат - значения LF/HF. Выбор именно этих показателей связан с тем, что их совместное интерпретирование позволяет соотнести уровень вегетативного баланса и общий тонус регуляторных систем.

Далее по этим показателям определяется 25\% и 75\% квартили для каждой выборки, которые являлись внутренними границами для построения классификационной матрицы по уровням адаптации. Выбор такого подхода обусловлен тем, что значения переменных, оказавшиеся между квартилями, можно считать нормой для данной выборки, так как они характерны для 50\% объектов [1].

\section{Практическая реализация}

В данной статье описаны исследования вариабельности сердечного ритма на основе показаний прибора Firstbeat Bodyguard, регистрирующего RRинтервалы.

Были проанализированы данные, полученные прибором в результате исследования 31 человека. Исследуемые в начале теста надевали на себя прибор и проводили свою обычную дневную деятельность. Исследования проводились на базе Международного научно-технического Центра информационных технологий и систем НАН и МОН Украины. Результаты эксперимента были записаны в текстовый файл в виде числовой последовательности $\mathrm{R}-\mathrm{R}$ интервалов, выраженных в миллисекундах. После записи результаты обрабатывались в программе, написанной с помощью пакета прикладных программ MATLAB. Программа работает следующим образом: создает папку для записи результатов, считывает данные с текстового документа с зарегистрированными R-R интервалами, после выбирается интервал времени, который пригоден для спектрального анализа, а именно запись трехсот R-R интервалов в состоянии покоя, в то время когда все исследуемые спят, далее обрабатывает результаты с помощью формул и алгоритмов спектрального анализа пакета MATLAB, после выполняется построение спектрограммы средствами MATLAB, и сохраняет результаты анализа и графики в созданную папку. 
Анализ полученных результатов

Проведя эксперимент с участием 31 человека и, проанализировав результаты, можно сделать следующие выводы.

В целом параметр HF\% понижен у 3-х человек. Повышение вероятно в состоянии покоя, во время сна, при частой гипервентиляции. Снижение - при физической нагрузке, стрессе, различных заболеваниях. Параметр LF\% повышен у 2-х человек, понижен у 1-го. Повышение вероятно при физических нагрузках, стрессе, различных функциональных или органических изменениях сердечно-сосудистой системы.

Снижение вероятно в покое, во время сна, при частой гипервентиляции. Параметр VLF\% понижен у 9-ти человек.

Повышение является вегетативным коррелятом тревоги, наблюдается при физической нагрузке, стрессе, органической патологии сердца. Снижение - в покое, во время беременности. В целом, параметр HFnorm был не в норме у 4-х человек, LFnorm был не в норме у 3-х человек, LF/HF - у 5-ти человек, ИЦ - у 1-го.

Далее приведена таблица результатов исследования вместе со спектрограммами исследуемых.

Таблиця 1.

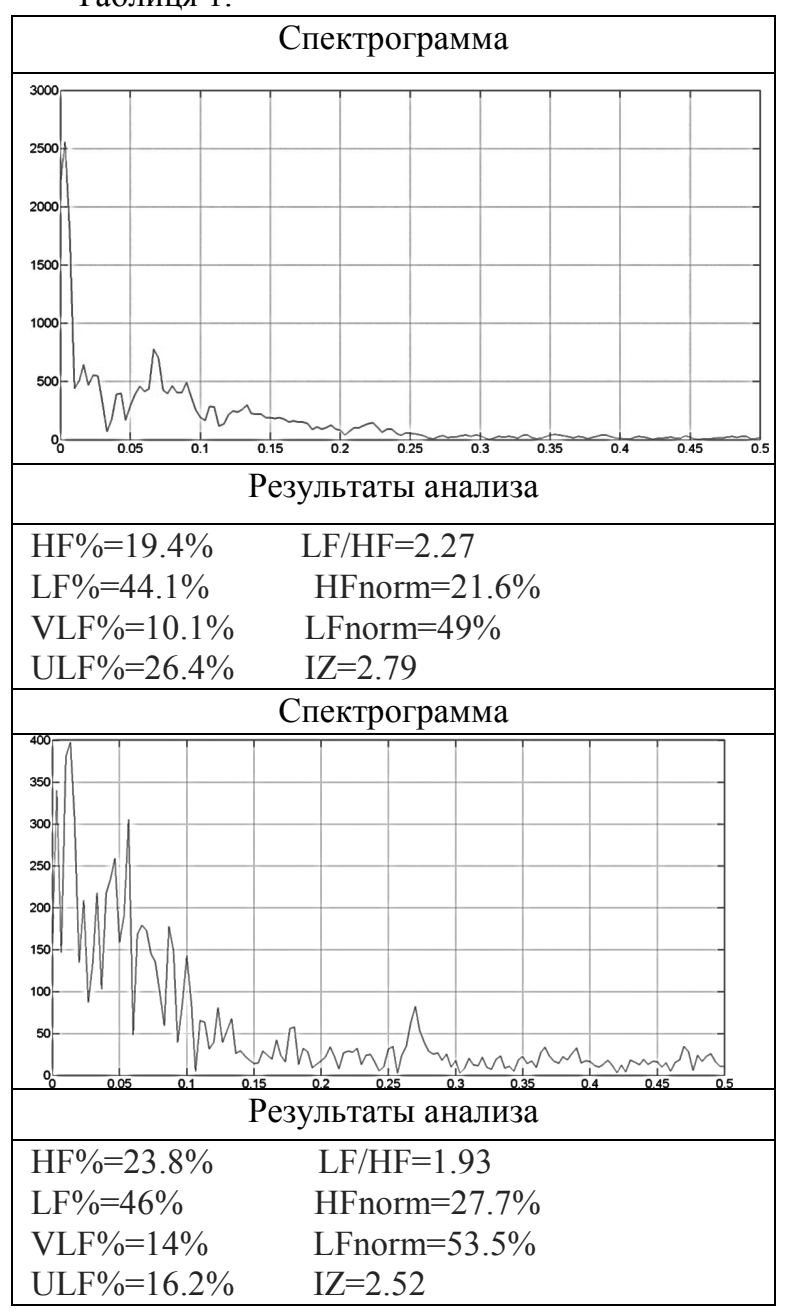

Продолжение табл. 1

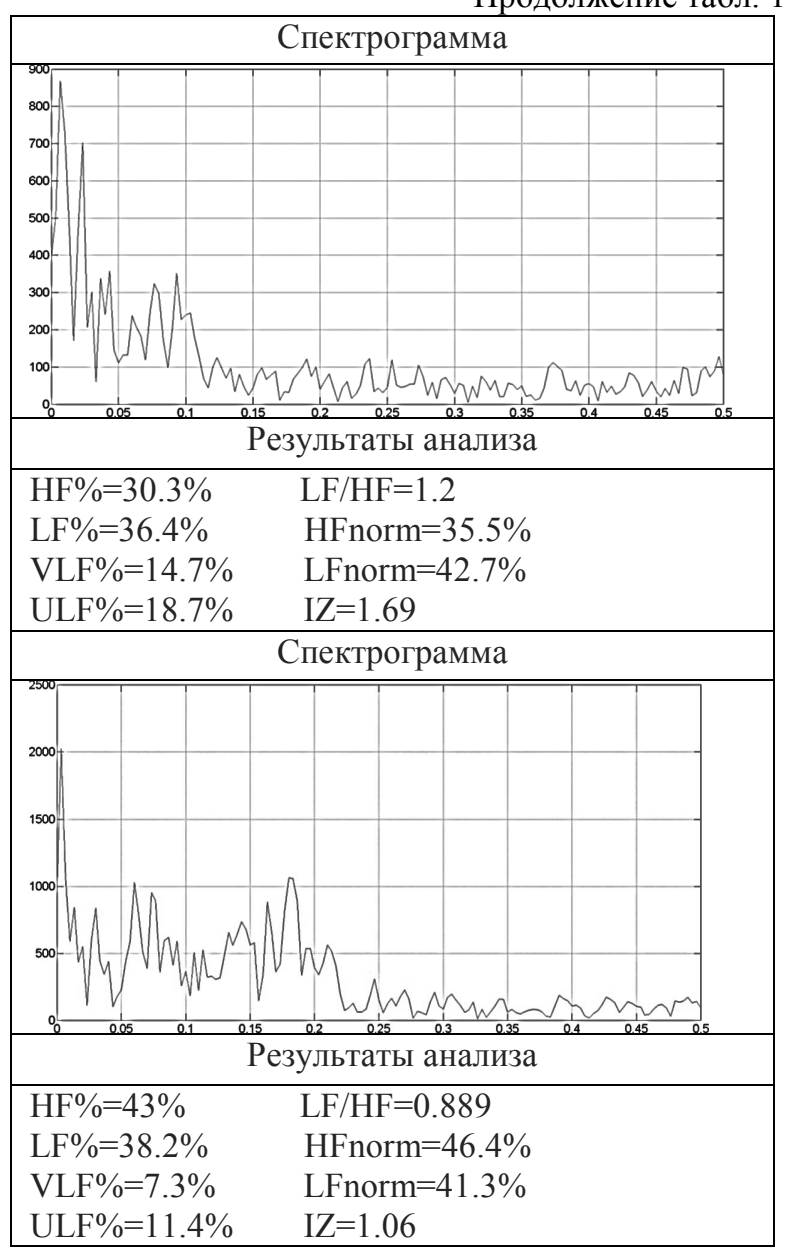

\section{Выводы}

Эксперимент является успешным, показания получены корректно.

В данной публикации представлен анализ вариабельности сердечного ритма, полученного при наблюдении на людях. Для анализа использовалась запись последовательности RR-интервалов человека во время вождения автомобиля.

Анализ результатов показал, что многие параметры были в пределах нормы, а параметры, которые вышли за них, не вошли в пределы патологий.

Применение анализа ВСР в качестве метода оценки адаптационных возможностей организма или текущего уровня стресса представляет практический интерес для различных областей прикладной физиологии, профессиональной и спортивной медицины, а также для социально-экологических исследований. Развитие донозологической диагностики сделало возможным выделение среди практически здоровых людей обширных групп лиц с высоким и очень высоким напряжением регуляторных систем, с повышенным риском срыва адаптации и появления патологических отклонений и заболеваний. Такие лица нуждаются в регулярном контроле уровня стресса и в рекомендациях по сохранению здоровья. 
На современном этапе практического использования метода анализа ВСР в прикладной физиологии к клинической медицине представленные выше подходы к физиологической и клинической интерпретации данных позволяют эффективно решать многие задачи диагностического и прогностического профиля, оценки функциональных состояний, контроля эффективности лечебно-профилактических воздействий и т.П. Однако, возможности этой методологии далеко не исчерпаны и ее развитие продолжается.

Дальнейшее направление развития методов анализа вариабельности сердечного ритма:

1. Изучение медленных волн 2-го порядка (VLF) и ультрамедленноволноволновых компонентов спектра сердечного ритма (ULF) - колебаний на частотах ниже 0,01 Гц (100), включая минутные и часовые волны (ультрадианные ритмы);

2. Исследование вариабельности сердечного ритма у детей и подростков, включая влияние школьных нагрузок и возрастно-половые аспекты.

\section{Литература}

1. Баевский Р. М., Кириллов О. И., Клецкин С. 3. Математический анализ изменений сердечного ритма при стрессе. Москва: Наука, 1984. 220 с.

2. Баевский Р. М., Мотылянская Р. Е. Ритм сердца у спортсменов. Москва: Физкультура и спорт, 1986. $142 \mathrm{c}$.

3. Баевский Р. М., Нидеккер И. К. Спектральный анализ функции сердечного автоматизма // Статистическая электрофизиология. Вильнюс, 1968. $751 \mathrm{c}$.
4. Баевский Р. М. Прогнозирование состояний на грани нормы и патологии. М.: Медицина, 1979. 295 c.

5. Баевский Р. М., Смирнова Т. М. Применение вариационной пульсометрии в оценке суточной динамики сердечного ритма у больных ишемической болезнью сердца и функциональными нарушениями сердечно- сосудистой системы // Кардиология. 1978. 18 (4). С. 44 - 50.

6. Худякова Л. А., Багатенкова А. И., Кулахметов Д. Р. Исследование вариабельности сердечного ритма с помощью статических и геометрических методов // Вісник НТУУ «КПІ». Серія приладобудування. 2017. Вип. 53(1). 116 с.

7. Баевский Р. М. Синусовая аритмия с точки зрения кибернетики. Москва: Наука, 1968.

8. Жемайтите Д. И., Варонецкас Г. А., Брожайтене Ю. Й., Жилюкас Г. А. Возможность оценки вегетативной регуляции сердечной деятельности у больных ИБС с использованием неинвазивных методом исследования. Киев: Кардиология, 1988.

9. Жемайтите Д. И. Кепеженас А., Мартинкенас А., Варонецкас Г. А. и др. Зависимость характеристик сердечного ритма и кровотока от возраста у здоровых и больных заболеваниями сердечнососудистой системы. Киев: Физиология человека, 1998.

10. Хаютин В. М., Бекбосынова М. С., Лукошкова Е. В. Тахикардия при глотании и спектральный анализ колебаний частоты сокращений сердца. Москва: Бюлл. Экспериментальной биологии мед. 1999.

УДК 612.72.2+616.12-00.8.3

Л. А. Худякова, А. И. Багатенкова, Д. Р. Кулахметов

Національний технічний університет України «Київський політехнічний інститут

імені Ггоря Сікорського», Київ, Украӥна

СПЕКТРАЛЬНИЙ МЕТОД АНАЛІЗУ ВАРІАБЕЛЬНОСТІ СЕРЦЕВОГО РИТМУ

Вступ. Проблема хронічного стресу, коли є постійна підвищена напруга регуляторних систем, стосується практично всього населення, але особливо важлива для окремих професійних груп, праця яких пов'язана 3 впливом комплексу стресових факторів. Це, зокрема, оператори комп'ютерних систем, диспетчери, водії, а також бізнесмени та адміністративно-управлінський апарат.

Аналіз ВСР є адекватним методом оцінки рівня стресу при їхній повсякденній діяльності.

Основна частина. Аналіз спектральної щільності потужності коливань дає інформацію про розподіл потужності залежно від частоти коливань. Застосування спектрального аналізу дозволяє кількісно оцінити різні частотні складові коливань ритму серця і наочно графічно представити співвідношення різних компонентів СР, що відображають активність певних ланок регуляторного механізму.

У статті розглянута інформаційна технологія у вигляді програмного забезпечення, використовуючи яку можна обробляти результати досліджень варіабельності серцевого ритму, які отримані за допомогою спеціалізованого приладу і збережені у вигляді числового масиву даних. Програмне забезпечення написано за допомогою Маtlab і досліджує масив даних за допомогою спектрального методу. Також проведено короткий аналіз результатів.

Висновки. На сучасному етапі практичного використання методу аналізу ВСР в прикладної фізіології до клінічній медицині представлені вище підходи до фізіологічної та клінічної інтерпретації даних дозволяють ефективно вирішувати багато завдань діагностичного і прогностичного профілю, оцінки функціональних станів, контролю ефективності лікувально-профілактичних впливів. Можливості цієї методології далеко не вичерпані і їі розвиток триває. Визначено подальші напрямки розвитку методів аналізу варіабельності серцевого ритму.

Ключові слова: варіабельність серцевого ритму, спектральний метод, RR-інтервал. 


\title{
L. A. Khudyakova, A. I. Bagatenkova, D. R. Kulakhmetov
}

National Technical University of Ukraine "Igor Sikorsky Kyiv Polytechnic Institute”, Kyiv, Ukraine SPECTRAL METHOD OF ANALYSIS OF HEART RHYTHM VARIABILITY

Introduction. The problem of chronic stress, when there is a constant increased tension of regulatory systems, affects almost the entire human population, but it is especially important for individual professional groups whose work is associated with the impact of a complex of stress factors. These are operators of computer systems, dispatchers, drivers, as well as businessmen and administrative and management office. Heart rhythm variability (HRV) analysis is an adequate method of assessing the level of stress in their daily activities.

Main part. The analysis of the spectral density of oscillation power gives information on the power distribution, depending on the frequency of oscillations. The application of spectral analysis allows to quantify the various frequency components of the heart rhythm (HR) fluctuations and graphically represent the ratio of various components of the HR reflecting the activity of certain parts of the regulatory mechanism.

This article considers information technology in the form of software, using which it is possible to process the results of studies of heart rate variability, which are obtained with the help of a specialized device and stored as a numerical array of data. The software is written using Matlab and it explores the array of data using the spectral method. A short analysis of the results was also carried out.

Conclusion. At the present stage of the practical use of the method of BCP analysis in applied physiology to clinical medicine, the above approaches to the physiological and clinical interpretation of data allow to effectively solve many tasks of the diagnostic and prognostic profile, evaluation of functional states, and the control of the effectiveness of therapeutic and prophylactic influences. The possibilities of this methodology are far from exhausted and its development continues. Further directions of development of methods of analysis of heart rate variability are determined.

Key words: heart rate variability, spectral method, RR-interval.

Надійшла до редакиії 19 квітня 2018 року

Рецензовано

11 травня 2018 року

\section{УДК $621: 615.849 .19$ \\ ІНТЕГРОВАНА ФОТОРЕГЕНЕРАЦІЯ БІОЛОГІЧНОЇ ТКАНИНИ ПРИ ПОРУШЕННЯХ ÏÏ СТАНУ}

\author{
Клочко Т. Р., Грибанова І. О., Скицюк В. І., Дастжерді А. Х. М. \\ Національний технічний університет Украӥни «Київський політехнічний інститут \\ імені Ігоря Сікорського», Київ, Украӥна \\ E-mail: t.klochko@,kpi.ua
}

\begin{abstract}
У статті йдеться про створення нових режимів лікувального випромінювання, які призначені для регенерації пошкоджених біологічних тканин.

Досліджено нові режими інтегрованого фізіотерапевтичного випромінювання, щзо формовані з урахуванням можливої зміни часових режимів та корекиії відповідно біологічній структурі, на яку здійснено вплив. Досліджено вплив теплових полів на глибину проникнення випромінення у фантомі біологічного багатомарового зразка, що утворюється внаслідок опромінення інтегрованою фізіотерапевтичною хвилею.

Ключові слова: фантом, регенерація, оптичне випромінювання, часові режими, біологічна тканина, інтегрована фізіотерапевтична хвиля.

\section{Вступ}

Дослідження регенерації тканин живого організму при хромотерапії демонструють хороші результати порівняно 3 стандартними методами лікування. Загоювання уражених, інфікованих тканин є складним, багаторівневим процесом. Саме

когерентне випромінювання з метою пришвидшення регенерації пошкоджених, відкритих, поверхневих ділянок шкіри. Це дозволяє ввести подібні методи у сферу невідкладної медичної допомоги, спортивну, військову та інші сфери медицини на основі використання такого типу лікування.
\end{abstract} тому актуально використовувати оптичне 